\title{
Erratum to: When Hunters Gather but Do Not Hunt, Playing with the State in the Forest: Jarawa Children's Changing World
}

\author{
Vishvajit Pandya
}

Erratum to:

Chapter 16 in: H. Terashima, B.S. Hewlett (eds.), Social Learning and Innovation in Contemporary Hunter-Gatherers, Replacement of Neanderthals by Modern Humans Series, 10.1007/978-4-431-55997-9_16

Following the publication of this book chapter [1], it has been brought to the publisher's attention that this chapter includes wording from the work of others without rephrasing and appropriate attribution.

Footnote 1 (p. 189) and footnote 3 (p. 191) as well as some text in paragraphs 2 and 3 on p. 190 (in section 16.2) were taken from [2].

The last paragraph on p. 192 finishing on p. 193 (section 16.3), the first paragraph on p. 193 (in section 16.4), footnote 4 (p. 193), and footnote 13 on p. 198 were taken from [3].
[1] Pandya V (2016) When Hunters Gather but Do Not Hunt, Playing with the State in the Forest: Jarawa Children's Changing World. In: Terashima H, Hewlett BS (eds) Social Learning and Innovation in Contemporary Hunter-Gatherers: Evolutionary and Ethnographic Perspectives. Springer Japan, Tokyo, pp 187-199.

[2] Atkinson L (2006) From play to knowledge: from visual to verbal?. Anthropol Matters J 8(2):1-17.

[3] Gray P (2008) Children Educate Themselves III: The Wisdom of Hunter-Gatherers. Psychology Today https:// www.psychologytoday.com/blog/freedom-learn/200808/chil dren-educate-themselves-iii-the-wisdom-hunter-gatherers 